\title{
Measurement of extent of spread of oesophageal squamous carcinoma by serial sectioning
}

\author{
K Y Lam, L T Ma, J Wong
}

\begin{abstract}
Objectives-(1) To examine the prevalence and extent of intramural metastasis in squamous cell carcinomas of the oesophagus so as to delineate the resection margins for these tumours; (2) to devise an appropriate method for measurement of these lesions which takes into account of the contraction of the specimens after resection.
\end{abstract}

Methods-Oesophagectomy specimens were prospectively collected from 96 patients (87 males, nine females) with primary oesophageal squamous cell carcinoma over a two year period. The sizes of the tumours were measured in situ, after resection and after application of muscle relaxant (to regain their in situ length). The specimens were then serially sectioned for histological examination.

Results-The sizes of the tumours measured after application of muscle relaxant roughly corresponded to those measured in situ. Intramural metastasis was observed in $26 \%$ of the cases. Sixty four per cent (16 cases) of these were on the oral side, $72 \%$ (18 cases) on the gastic side, and $25 \%$ (nine cases) on both sides of the tumours. The most distant extent of intramural metastasis from the primary tumour was from $0.5 \mathrm{~cm}$ to $7.7 \mathrm{~cm}$ (mean = $3.4 \mathrm{~cm}$ ) on the oral side, and 0.5 to $9.5 \mathrm{~cm}$ (mean $4 \mathrm{~cm}$ ) on the gastric aspect of the tumour. Intramural metastasis was seen only in patients in whom the primary cancer had deep muscle infiltration. Multiple neoplastic lesions could be detected in 33\% of the patients. Both intramural metastasis and multiple neoplastic lesions were associated with extensive lymph node infiltration. However, they had different histological features and extent of infiltration.

Conclusions-Intramural metastasis was frequently observed in oesophageal squamous cell carcinoma. This implies that excision with wide margins should be considered for local control of the disease. (f Clin Pathol 1996;49:124-129)

Keywords: oesophagus, squamous carcinoma, intramural metastasis, multiple primaries.

Oesophageal cancers are tumours with a high mortality rate and a high incidence in oriental populations such as those of China and Hong
Kong. ${ }^{12}$ About $90 \%$ of these cancers are squamous cell carcinomas. ${ }^{3}$ The poor prognosis of these patients is partly a result of late presentation of the lesions and difficulties in achieving curative resection of the tumours. Long term survival after excision of the oesophageal cancer is possible in only a small minority of the patients. For instance, the five year survival of patients with squamous cell carcinoma after curative resection is $31 \%$, and after palliative resection $15 \%$, in Hong Kong. ${ }^{4}$ Thus the primary objective of the treatment is to relieve the obstruction to allow the patient to swallow after the operation. Anastomotic recurrence of the tumour will defeat the purpose of the resection. This is found in $6.1 \%$ of patients who have undergone resection of oesophageal squamous cell carcinoma in our locality. ${ }^{5}$ Recurrence is closely related to the margin of clearance at operation, which is principally determined by the extent of intramural spread of the primary tumour in the oesophagus. Intramural metastasis is also one of the most important prognostic factors for oesophageal carcinoma. ${ }^{6-11}$ Therefore guidelines have to be established from this known behaviour of the tumour in order to decide the extent of the resection.

We report a prospective study of the extent of intramural metastasis of oesophageal squamous cell carcinoma to define a safety margin for resection of the tumour. Since shrinkage of specimens occurs after resection, which may account for the discrepancy claimed by the surgeons and pathologists regarding the length of the margins, ${ }^{12}$ we devised a method of stretching the specimens so that the measurements are representative of the in situ values.

\section{Methods}

Patients with resectable primary oesophageal carcinomas treated in Queen Mary Hospital in Hong Kong from January 1984 to December 1986 were evaluated prospectively. In cases who had undergone Lewis-Tanner operations, measurement of the longitudinal length of oesophageal tumours was made at operation before they were removed from the patients (in situ). Each of the resected fresh specimens was opened along the border in such a way as to avoid cutting through the tumour, and it was then laid out flat. The lengths of the tumours were again recorded. The specimens were then taken fresh as soon as possible (within 20 minutes) to the pathology department from the 
operating room by a research assistant. The measurements of the size of these tumours were repeated immediately they reached the department of pathology. The specimens were then put into a preprepared solution for two minutes to allow them regaining their in situ lengths. This solution was a mixture of $1 \mathrm{ml}$ $1 \%$ procaine hydrochloride (Novocain, Winthrop), a muscle relaxant, with $500 \mathrm{ml} 0.9 \%$ sodium chloride heated to $37^{\circ} \mathrm{C}$. The specimens were pinned on a foam board by gentle traction and photographed in a fresh state for record keeping. The length of the tumours was measured again.

Three days after fixation in $10 \%$ formalin, serial sectioning of the tumours in horizontal and longitudinal planes was done. The entire specimen was then cut into slices longitudinally at intervals of $0.5 \mathrm{~cm}$ in width with a razor and embedded in paraffin wax blocks. The blocks were labelled and numbered consecutively using the centres of each tumour as the reference point (fig 1). The sections from the paraffin wax blocks were processed with routine haematoxylin and eosin staining and histologically examined.

Only squamous cell carcinomas arising from the oesophagus in Chinese patients were included in this study. Age and sex of the patients and the location of the tumours were recorded. The tumours were classified into well, moderately, and poorly differentiated according to the WHO classification. ${ }^{13}$ Each of the sections from the primary oesophageal tumour was evaluated for the depth of infiltration of the carcinoma (in the mucosa, submucosa, circular muscle, longitudinal muscle, and adventitia) through the wall of the oesophagus. Lymph node metastases and tumour vascular permeation were also identified. The presence and location of intramural metastasis were noted. We defined intramural metastasis as a metastatic lesion that is clearly separated from the primary tumour and invading the oesophageal or gastric wall but not surrounded by endothelium. In each specimen, the greatest distance of intramural metastasis from the primary tumour was measured on each side (proximal or distal) of the primary tumour according to histological examination of the slides from the labelled blocks. In addition, the presence and number of multiple neoplastic lesions in the oesophagus were determined. Multiple neoplastic lesions are defined as lesions (dysplasia, carcinoma in situ, or invasive carcinoma) that are distant from one another by at least $1 \mathrm{~cm}$. In each case, the largest sized tumour was taken as the primary lesion while the smaller ones as associated lesions, or, if they were of the same size, the tumour with deepest invasion was

Table 1 The four sets of measurements of the tumour and their relations

\begin{tabular}{llll}
\hline & $\begin{array}{l}\text { Range } \\
(\mathrm{cm})\end{array}$ & $\begin{array}{l}\text { Mean }(\mathrm{SD}) \\
(\mathrm{cm})\end{array}$ & $\begin{array}{l}\text { Total length of tumour in } \\
\text { the 46 specimens }(\mathrm{cm})\end{array}$ \\
\hline In situ & $1 \cdot 0-12.5$ & $6 \cdot 28(2 \cdot 45)$ & $289(100 \%)^{*}$ \\
In theatre & $1 \cdot 0-12 \cdot 5$ & $5 \cdot 65(2 \cdot 14)$ & $260(90 \%)$ \\
In resected specimen & $1 \cdot 1-12.5$ & $5 \cdot 67(2 \cdot 37)$ & $261(90 \%)$ \\
After relaxation & $1 \cdot 3-12.5$ & $6 \cdot 41(2 \cdot 53)$ & $295(102 \%)$ \\
\hline
\end{tabular}

* The in situ measurement was used as the standard (100\%) for comparison.

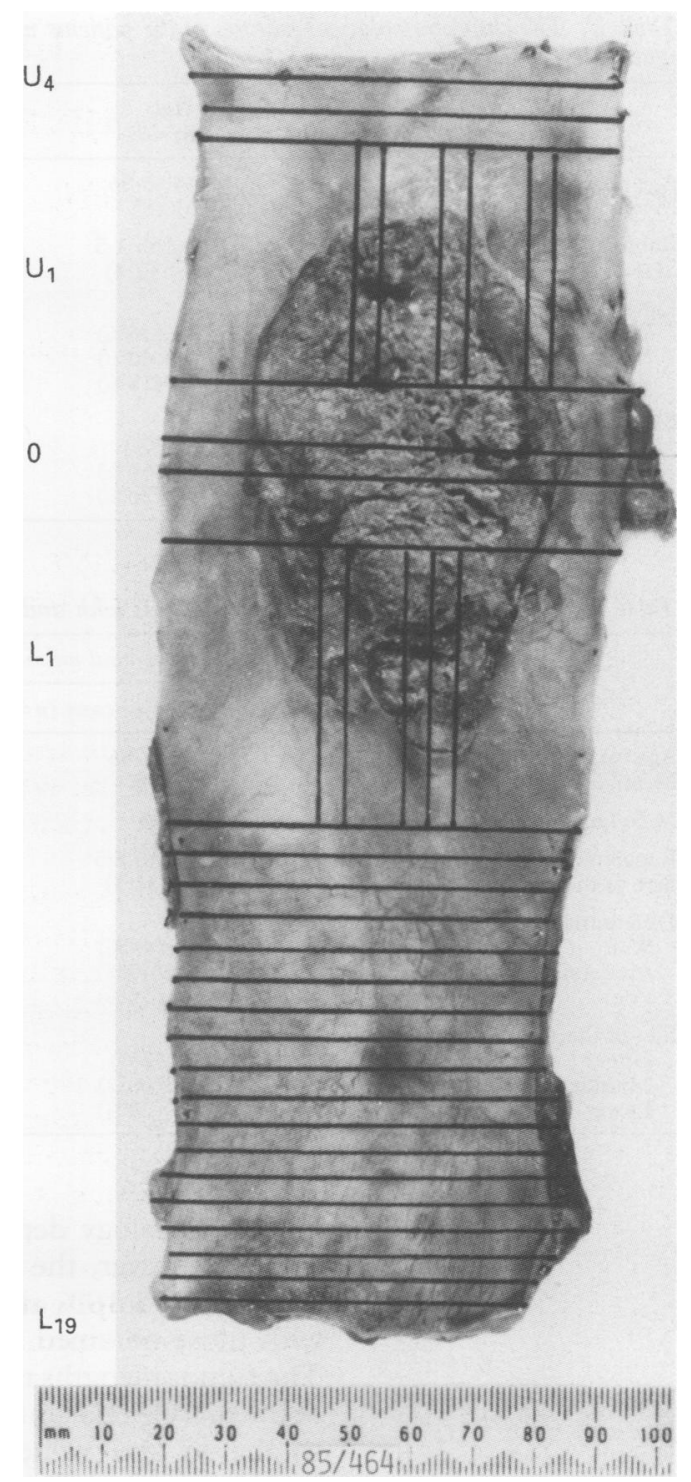

Figure 1 The resected oesophagus was cut into slices by a serial blocking technique after fixation. The tumour was cut into both longitudinal and horizontal sections. The remaining specimen is divided into upper/proximal (U) and lower/distal $(L)$ proportion with the centre of tumour as the reference point. They were then cut horizontally at $5 \mathrm{~mm}$ intervals and labelled consecutively, with the smallest numbered block one nearest the tumour.

regarded as the primary lesion. The histological features of intramural metastasis and multiple neoplastic lesions were both identified.

\section{STATISTICS}

Statistical analysis was performed using Fisher's exact test, $\chi^{2}$ test, and Student's $t$ test. A $p$ value of less than 0.05 was considered to be significant.

\section{Results}

The measurements of the tumour length and the relative proportion of shrinkage for the four states of the specimens (that is, in situ, in the operation theatre after resection, and in the pathology department before and after application of muscle relaxant) in 46 cases of oesophageal squamous cell carcinoma are shown in table 1 . The lengths of the resected tumours measured in the operation theatre and 
Table 2 The clinicopathological features of the patients with resected oesophageal squamous cell carcinomas

\begin{tabular}{llll}
\hline & $\begin{array}{l}\text { Male } \\
(n=87)\end{array}$ & $\begin{array}{l}\text { Female } \\
(n=9)\end{array}$ & $\begin{array}{l}\text { Whole group } \\
(n=96)\end{array}$ \\
\hline $\begin{array}{l}\text { Age range, years } \\
\text { Mean age (SD), years }\end{array}$ & $\begin{array}{l}44 \text { to } 86 \\
61(8)\end{array}$ & $\begin{array}{l}52 \text { to } 74 \\
63(7)\end{array}$ & $\begin{array}{l}44 \text { to } 86 \\
61(8)\end{array}$ \\
$\begin{array}{l}\text { Range of the size of the tumour, cm } \\
\text { Size of the tumour, mean (SD), cm }\end{array}$ & $\begin{array}{l}1 \cdot 3 \text { to } 1 \cdot 5 \\
6 \cdot 1(2 \cdot 4)\end{array}$ & $\begin{array}{l}2 \cdot 2 \text { to } 9 \cdot 7 \\
6 \cdot 3(2 \cdot 8)\end{array}$ & $\begin{array}{l}1 \cdot 3 \text { to } 12.5 \\
6 \cdot 1(2 \cdot 4)\end{array}$ \\
$\begin{array}{l}\text { Differentiation of the tumour, n (\%) } \\
\text { Well }\end{array}$ & $31(36 \%)$ & $4(44 \%)$ & $35(36 \%)$ \\
$\quad \begin{array}{l}\text { Moderate } \\
\text { Poor }\end{array}$ & $40(46 \%)$ & $4(44 \%)$ & $44(46 \%)$ \\
Site of the main lesion, n (\%) & $16(18 \%)$ & $1(12 \%)$ & $17(18 \%)$ \\
$\quad$ Upper & $7(8 \%)$ & $1(11 \%)$ & $8(8 \%)$ \\
$\quad \begin{array}{l}\text { Middle } \\
\text { Lower }\end{array}$ & $57(66 \%)$ & $6(67 \%)$ & $63(66 \%)$ \\
\hline
\end{tabular}

Table 3 Clinicopathological features of patients with and without intramural metastasis

\begin{tabular}{lll}
\hline & \multicolumn{2}{l}{ Intramural metastasis } \\
\cline { 2 - 3 } & Positive cases $(n=25)$ & Negative cases $(n=71)$ \\
\hline Age range, years & 44 to 86 & 45 to 78 \\
Mean age (SD), years & $61(9)$ & $62(8)$ \\
Male/female & $24 / 63$ & $1 / 8$ \\
Range of size of the tumour, cm & $4 \cdot 3$ to $8 \cdot 5$ & $1 \cdot 3$ to $12 \cdot 5$ \\
Size of the tumour, mean (SD), cm & $6 \cdot 3(1 \cdot 5)$ & $6 \cdot 0(2 \cdot 7)$ \\
Differentiation of the tumour, n (\%) & & \\
$\quad$ Well & $11(44 \%)$ & $24(34 \%)$ \\
$\quad$ Moderate & $10(40 \%)$ & $34(48 \%)$ \\
$\quad$ Poor & $4(16 \%)$ & $13(18 \%)$ \\
Site of the main lesion, $\mathrm{n}(\%)$ & $2(8 \%)$ & $6(8 \%)$ \\
$\quad$ Upper & $17(68 \%)$ & $46(65 \%)$ \\
Middle & $6(24 \%)$ & $19(27 \%)$ \\
$\quad$ Lower & & \\
\hline
\end{tabular}

in the pathology department were nearly the same. However, the lengths measured in this state showed $10 \%$ shrinkage when compared with those obtained by in situ measurements. The tumour lengths measured after application of the muscle relaxant corresponded reasonably to the in situ values $(102 \%$ of the in situ measurements). The measurements after application of the relaxant were thus used in the other parts of the study.

Ninety six patients ( 87 males, nine females) with resected primary oesophageal carcinomas were included in the study. The clinicopathological features of these cases are shown in table 2. The mean age of the patients was

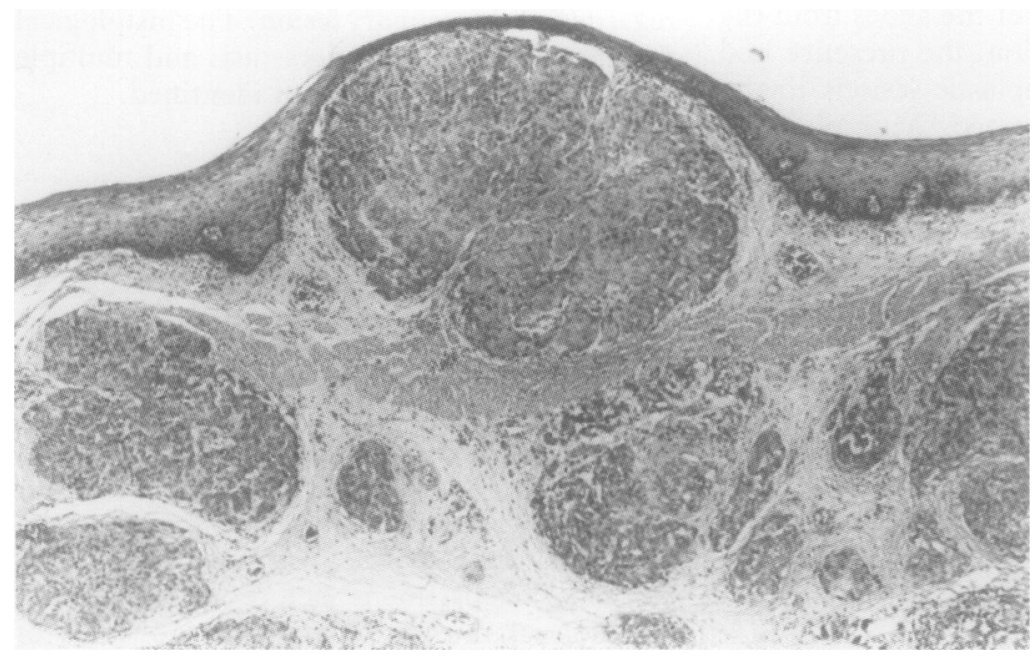

Figure 2 Intramural metastases in the oesophageal wall. The lesions present as nodules and are covered by intact epithelium. Scanty or no significant inflammation is present. (Haematoxylin and eosin, original magnification $\times 115$.)
61 years (range 44 to 86 ) and the mean size of the main tumour was $6.1 \mathrm{~cm}$ (ranging from 1.3 to $12.5 \mathrm{~cm}$ ). Thirty six per cent of the squamous cell carcinomas (35 cases) were well differentiated, $46 \%$ moderately differentiated ( 44 cases), and $18 \%$ poorly differentiated (17 cases). Most of the cases were found in the middle portion of the oesophagus ( $8 \%$ in the upper, $66 \%$ in the middle, and $26 \%$ in the lower portion). There was no significant difference between males and females with regard to the age distribution $(\mathrm{p}=0.42, \mathrm{z}=0.8, t$ test $)$ of the patients, or the size $(\mathrm{p}=0.84, \mathrm{z}=0 \cdot 2, t$ test $)$, differentiation ( $p=0 \cdot 25$, Fisher exact test), and site ( $p=0.99$, Fisher exact test) of the tumours.

Intramural metastasis was found in $26 \%$ of the patients ( 25 cases; 24 males and one female) after serial sectioning of the specimens. The clinicopathological features of the cases with and without intramural metastasis are given in table 3 . The male to female ratio was similar in both groups of patients ( $p=0 \cdot 44$, Fisher's exact test). There was no significant difference between the patients with and without intramural metastases with regard to age $(\mathrm{p}=$ $0.62, \mathrm{z}=0.49, t$ test $)$, size $(\mathrm{p}=0.5, \mathrm{z}=0.68$, $t$ test $)$, site $\left(\mathrm{p}=0.96, \chi^{2}=0.88, \mathrm{df}=2\right)$, and differentiation $\left(\mathrm{p}=0.66, \chi^{2}=0.83, \mathrm{df}=2\right)$ of the tumours.

Intramural metastases usually consisted of nodular masses in the submucosa or the muscles of the specimens (fig 2). Scanty or no inflammatory cells were present around the lesions. Metastases could be seen in the oral or the gastric side of the primary oesophageal cancer or in both. Sixty four per cent of the patients (16 cases) in this study had intramural metastasis on the oral side, $72 \%$ on the gastric side (18 cases), and $25 \%$ on both sides (nine cases). Intramural metastases on the oral side of the specimens were separated from the main tumour by from 0.5 to $7.7 \mathrm{~cm}$ (mean $=3.4 \mathrm{~cm}$, median $=2.5 \mathrm{~cm}, \mathrm{SD}=2.2 \mathrm{~cm}$ ), while those on the gastric side were from 0.5 to $9.5 \mathrm{~cm}$ away (mean $=4 \mathrm{~cm}$, median $=2.5 \mathrm{~cm}, \mathrm{SD}=3.4 \mathrm{~cm}$ ). No significant difference was identified in the extent of infiltration of intramural metastases on either the oral or the gastic side $(p=0.54$. $\mathrm{z}=0.62, t$ test).

Multiple neoplastic lesions were detected in $33 \%$ of the patients ( 32 cases; 30 males and two females). The lesions were usually flat, diffuse or ulcerated, and with a prominent inflammatory reaction around them. Of these 32 cases, $22 \%$ (seven cases) were invasive carcinomas, $19 \%$ (six cases) were carconoma in situ, and $59 \%$ (19 cases) were dysplastic lesions. The proximal extent of multiple neoplastic lesions from the primary tumours was $14.5 \mathrm{~cm}$ while the distal extent was $13.1 \mathrm{~cm}$. The clinicopathological features of patients with and without multiple neoplastic lesions are given in table 4 . There was no significant sex and age difference in patients with and without multiple neoplastic lesions $(p=0.7$, Fisher's exact test for sex; $p=0.58, z=0.56$ for age by $t$ test). The size of the primary tumours in patients with multiple neoplastic lesions was not different from that from patients with single oesophageal carcinomas $(p=0 \cdot 84, z=0 \cdot 2$, 
Table 4 Clinicopathological features of patients with and without multiple neoplastic lesions

\begin{tabular}{lll}
\hline & \multicolumn{2}{l}{ Multiple neoplastic lesions } \\
\cline { 2 - 3 } & Positive cases $(n=32)$ & Negative cases $(n=64)$ \\
\hline Age range, years & 48 to 74 & 44 to 86 \\
Mean age (SD), years & $62(8)$ & $61(9)$ \\
Male/female & $30 / 2$ & $57 / 7$ \\
Range of size of the tumour, cm & 2 to 10 & $1 \cdot 3$ to $12 \cdot 5$ \\
Size of the tumour, mean (SD), cm & $6 \cdot 2(2 \cdot 1)$ & $6 \cdot 1(2 \cdot 6)$ \\
Intramural metastases, $\mathrm{n}$ & 11 & 21 \\
$\quad$ Positive cases & 14 & 50 \\
\hline Negative cases & & \\
\hline
\end{tabular}

$t$ test). Furthermore, there was no relation between the presence of intramural metastasis and multiple neoplastic lesions $\left(p=0 \cdot 19, \chi^{2}=\right.$ $1 \cdot 73, \mathrm{df}=1$ ).

Lymph node metastases were present in $64 \%$ of the 96 patients with oesophageal squamous cell carcinoma. They were identified in $80 \%$ of patients with intramural metastasis (20 of 25 cases) and in $58 \%$ of patients without intramural metastasis (41 out of 71 cases). Thus there was a significant difference in the frequency of lymph node infiltration in patients with and without intramural metastasis $(p=$ $0.047, \chi^{2}=3.95, \mathrm{df}=1$ ). In patients with multiple neoplastic lesions, $78 \%$ (25 cases) had lymph node infiltration by carcinoma, while in patients without multiple neoplastic lesions, $56 \%$ (36 cases) had lymph node metastases. The association between lymph nodes metastases and multiple neoplastic lesions $(p=0.04$, $\chi^{2}=4 \cdot 41, \mathrm{df}=1$ ) was significant.

Vascular permeation by tumours was seen in $17 \%$ of the patients (16 cases). It was often seen at the base of the tumour but could occasionally be identified at a distance from the primary tumour (at a maximum distance of $5 \mathrm{~cm}$ from the main tumour). The condition was observed in half the cases with intramural metastasis (nine of 18 cases) and in $10 \%$ of patients without intramural metastasis (seven of 71 cases). Therefore vascular permeation by tumours was found to be associated with intramural metastasis $\left(p<0.01, \chi^{2}=15.69\right)$. It was further observed that vascular permeation was found in $28 \%$ of cases with multiple neoplastic lesions (nine cases) and in $11 \%$ of patients without multiple neoplastic lesions (seven cases). There was significant association between vascular permeation by tumours and multiple neoplastic lesions $\left(\mathrm{p}=0.03, \chi^{2}=4.54\right.$, $\mathrm{df}=1)$. Lymph node metastases were not related to vascular permeation by tumours $(p=$ $0 \cdot 044$, Fisher's exact test).

The various clinicopathological features associated with the depth of oesophageal carcinomas are given in table 5. Early oesophageal squamous cell carcinomas were present in three cases in which the carcinoma invaded up to the submucosa. There was no difference in age $(p=0.96, z=0.052, t$ test $)$ or sex $(p=$ $0 \cdot 9$, Fisher's exact test) between tumours with transmural infiltration and those confined to the wall of the oesophagus. On the other hand, there was significant relation between the depth of tumour infiltration and the size of the tumour $(p=0.009, z=2.6, t$ test $)$. Although vascular permeation was only present in those cases where there was at least infiltration in the longitudinal muscle layer of the oesophagus, vascular permeation by tumours was not related to the depth of infiltration $(p=0.6$, Fisher's exact test). On the other hand, lymph node metastases were significantly correlated with a depth of tumour infiltration $\left(p=0.02, \chi^{2}=\right.$ $5 \cdot 18, \mathrm{df}=1$ ). Intramural metastasis was also seen only in patients with deep muscle (longitudinal muscle) infiltration. However, there was no significant relation between the level of infiltration by the primary tumour and intramural metastasis $(p=0.07$, Fisher's exact test).

\section{Discussion}

Intramural metastasis in oesophageal cancers was first reported by Watson in $1933,{ }^{6}$ but since then little attention has been paid to it in the English literature except for a few reports. ${ }^{7-13}$ The incidence of intramural metastasis observed by these research groups varied greatly from $9 \%$ to $35 \%$. The incidence detected in the current study $(26 \%)$ by serial sections of the entire surgically resected oesophagus also fell within this range. It is thus clear that intramural metastasis is frequently observed in oesophageal squamous cell carcinomas.

Table 5 The relation of depth of infiltration of carcinoma in the wall of oesophagus to other clinicopathological factors

\begin{tabular}{|c|c|c|c|c|c|}
\hline & \multicolumn{5}{|c|}{ Level of involvement of the oesophageal wall by carcinoma } \\
\hline & Mucosa & Submucosa & Circular muscle & Longitudinal muscle & Adventitia \\
\hline Total number of cases & 0 & 3 & 5 & 17 & 71 \\
\hline Male/female & $0 / 0$ & $3 / 0$ & $3 / 2$ & $16 / 1$ & $65 / 6$ \\
\hline $\begin{array}{l}\text { Age range, years } \\
\text { Mean age (SD), years }\end{array}$ & $\begin{array}{l}- \\
-\end{array}$ & $\begin{array}{l}49 \text { to } 71 \\
61(11)\end{array}$ & $\begin{array}{l}53 \text { to } 76 \\
63(4)\end{array}$ & $\begin{array}{l}48 \text { to } 77 \\
61(8)\end{array}$ & $\begin{array}{l}44 \text { to } 86 \\
61(9)\end{array}$ \\
\hline $\begin{array}{l}\text { Size range }(\mathrm{cm}) \\
\text { Mean size, }(\mathrm{SD}), \mathrm{cm}\end{array}$ & $\begin{array}{l}- \\
-\end{array}$ & $\begin{array}{l}2 \cdot 3 \text { to } 2 \cdot 6 \\
2 \cdot 4(0 \cdot 2)\end{array}$ & $\begin{array}{l}1.3 \text { to } 8 \cdot 5 \\
3 \cdot 8(2 \cdot 8)\end{array}$ & $\begin{array}{l}2 \text { to } 10 \cdot 7 \\
5 \cdot 8(2 \cdot 4)\end{array}$ & $\begin{array}{l}2 \cdot 1 \text { to } 12 \cdot 5 \\
6 \cdot 5(2 \cdot 3)\end{array}$ \\
\hline $\begin{array}{l}\text { Lymph node infiltration, } \mathbf{n} \\
\text { Positive cases } \\
\text { Negative cases }\end{array}$ & $\begin{array}{l}0 \\
0\end{array}$ & $\begin{array}{l}0 \\
3\end{array}$ & $\begin{array}{l}2 \\
3\end{array}$ & $\begin{array}{l}8 \\
9\end{array}$ & $\begin{array}{l}51 \\
20\end{array}$ \\
\hline $\begin{array}{l}\text { Vascular permeation by tumour, } \mathrm{n} \\
\text { Positive cases } \\
\text { Negative cases }\end{array}$ & $\begin{array}{l}0 \\
0\end{array}$ & $\begin{array}{l}0 \\
3\end{array}$ & $\begin{array}{l}0 \\
5\end{array}$ & $\begin{array}{l}3 \\
14\end{array}$ & $\begin{array}{l}13 \\
58\end{array}$ \\
\hline $\begin{array}{l}\text { Intramural tumour metastasis, } \mathrm{n} \\
\text { Positive cases } \\
\text { Negative cases }\end{array}$ & $\begin{array}{l}0 \\
0\end{array}$ & $\begin{array}{l}0 \\
3\end{array}$ & $\begin{array}{l}0 \\
5\end{array}$ & $\begin{array}{l}3 \\
14\end{array}$ & $\begin{array}{l}22 \\
49\end{array}$ \\
\hline
\end{tabular}


There is no consensus so far on whether intramural metastases are more commonly observed on the proximal (oral) side or the distal (gastric) side of the primary lesion. In the previous reports, as well as in our present study, the number of cases with intramural metastases on the proximal and the distal side is almost the same. However, most studies (except that of Kato and his colleagues ${ }^{9}$ ) have shown a tendency for there to be more metastases on the distal side. Nevertheless, these metastases can occur on both sides of the primary tumour and the published reports do not indicate a strong predilection for direction of spread.

Lymph node infiltration, which we identified in $80 \%$ of patients with intramural metastasis in this study, was significantly associated with intramural metastasis. The high frequency of lymph node metastases in the presence of intramural metastasis has also been noted in other studies. ${ }^{8-10}$ These findings concur with the theory that intramural metastases may originate in the intramural lymphatic spread of the carcinoma. This also suggests that intramural metastases may be a secondary focus of the involved lymph nodes, in addition to the primary carcinoma. On the other hand, vascular permeation was seen in $50 \%$ of patients with intramural metastasis. Although vascular permeation was associated with intramural metastasis in our study, its frequency in patients with intramural metastases was not as high as that of lymph nodes metastases.

Intramural metastases was not present in early oesophageal squamous cell carcinomas which we examined in this study. They were only found when the tumours had invaded into the longitudinal muscle. However, no significant association was noted between the depth of invasion and the presence of intramural metastasis. The other clinicopathologic variables like age, sex of the patient, and location, size, and site of the primary tumours were not related to the presence of intramural metastases. Furthermore, there was no relation between multiple neoplastic lesions and intramural metastasis.

Anastomotic recurrence has been reported to be related to the length of the resection margin from the primary oesophageal carcinoma. ${ }^{5}$ Careful attention must therefore be paid to the choice of margins during operations on carcinoma of the oesophagus. In addition, shrinkage of the oesophageal tissue may occur after operation. ${ }^{12}$ In this study, we propose a method-using muscle relaxant on the fresh tissue-to regain the in situ lengths of the tumours so as to obtain representative measurements of the extent of intramural metastases. However, the lengths of the tumours obtained by this method appear to be slightly greater than the in situ length $(102 \%$ of the in situ length, see table 1), probably because of relaxation of the numerous myofibroblasts in the tumour stroma. The second drawback in this investigation lies in the confidence limits of the measurement of the extent of intramural metastasis. This is no better than $0.5 \mathrm{~cm}$, as the blocks were taken at $0.5 \mathrm{~cm}$ intervals. Nevertheless, the most distant extent of the intramural metastases found in this study was $7.7 \mathrm{~cm}$ proximal to the primary tumour and $9.5 \mathrm{~cm}$ distal. The results obtained from the present study are comparable with the clinical findings reported previously in our hospital. ${ }^{5}$ In that study, a proximal resection margin of less than $5 \mathrm{~cm}$ measured in situ was found to have a $20 \%$ risk of anastomotic recurrence, and a margin of between 5 and $10 \mathrm{~cm}$ had only an $8 \%$ risk. Thus these findings indicate that long resection margins are necessary for complete clearance of oesophageal carcinomas. This is easier to achieve on the distal margin rather than on the proximal one since a longer proximal margin would need a pharyngolaryngectomy and the voice is not preserved.

Multiple neoplastic lesions are common in patients with oesophageal cancer. ${ }^{14}{ }^{15}$ This may be related to the impact of external factors like smoking and alcohol intake on carcinogenesis in this group of tumours. In the present study, multiple neoplastic lesions were detected in $33 \%$ of patients with oesophageal squamous cell carcinoma. As in the study by Kuwano et $a l,{ }^{15}$ we found no significant difference in sex or age of our patients or the size of the primary lesion between patients with single tumours and those with multiple neoplastic lesions in the oesophagus. On the other hand, lymph node metastases and vascular permeation were more common in patients with multiple neoplastic lesions. The proximal extent of the lesions from the primary tumour was $14.5 \mathrm{~cm}$ while the distal extent was $13 \cdot 1 \mathrm{~cm}$. Thus when multiple neoplastic lesions were found in the oesophagus it was difficult to achieve a clear proximal margin. Microscopically, multiple neoplastic lesions are flat, diffuse, or ulcerated, with prominent inflammatory reaction in the tumour stroma, in contrast to intramural metastases which are usually nodular masses with intact overlying epithelium, with scanty or no inflammatory cells. Thus multiple neoplastic lesions are different from intramural metastases in the histological features and the extent of involvement in the oesophagus.

In summary, intramural metastasis are frequently observed in oesophageal squamous cell carcinomas. Recurrent and possibly persistent disease is the rule with surgical treatment alone. In the light of this, it is important to have wide resection margins as well as adjuvant treatments to control the local and systemic disease process in the treatment of oesophageal carcinoma.

1 Parkin DM, Laara E, Muir CS. Estimates of the worldwide frequency of sixteen major cancers in 1980. Int $\mathcal{F}$ Cancer 1988;41:184-97.

2 Moses FM. Squamous cell carcinoma of the esophagus. Nature history, incidence, etiology, and complications. Gastroenterol Clin North Am 1991;20:703-16.

3 Lam KY, Loke SL, Ma LT. Histochemistry of mucin secreting components in mucoepidermoid and adenosquamous carcinoma of the oesophagus. 7 Clin Pathol 1993;46:1011-5.

4 Law SYK, Fok M, Cheng SWK, Wong J. A comparison of outcome after resection for squamous cell carcinomas and adenocarcinomas of the esophagus and cardia. Surg and adenocarcinomas of the esop

5 Tam PC, Siu KF, Cheung HC, Ma L, Wong J. Local recurrences after subtotal esophagectomy for squamous cell carcinoma. Ann Surg 1987;205:189-94.

6 Watson WL. Carcinoma of the esophagus. Surg Gynecol Obstet 1933;56:884-97. 
7 Burgess HM, Baggenstoss AH, Moersch HJ, Clagett OT. Carcinoma of the esophagus: a clinicopathologic study. Surg Clin North Am 1951;31:965-76.

8 Takubo K, Sasajima K, Yamashita K, Tanaka Y, Fujita K. Prognostic significance of intramural metastasis in patients with esophageal carcinoma. Cancer 1990;65:1816-9.

9 Kato H, Tachimori Y, Watanabe H, et al. Intramural metastasis of thoracic esophageal carcinoma. Int $\mathcal{F}$ Cancer 1992; 50:49-52.

10 Maeta $M$, Kondo A, Shibata S, Yamashiro $H$, Murakami A, Kaibara N. Esophageal cancer associated with multiple cancerous lesions: clinicopathologic comparisons between multiple primary and intramural metastatic lesions. Gastroenterol fpn 1993;28:187-92.
11 Fukuzumi N. Intramural spread of esophageal carcinoma. Surg Pathol 1994;5:269-94.

12 Siu KF, Cheung HC, Wong J. Shrinkage of the esophagus after resection for carcinoma. Ann Surg 1986;23:173-6.

13 Watanabe H, Jass JR, Sobin LH. Histological classification of oesophageal tumours. In: Histological typing of oesophageal and gastric tumours, 2nd edn. Berlin: SpringerVerlag, 1990:13.

14 Mizobuchi S, Kato H, Tachimori Y, Watanabe H, Yamaguchi $H$, Itabashi $M$. Multiple primary carcinoma of the oesophagus. Surg Oncol 1993;2:249-53.

15 Kuwano H, Ohno S, Matsuda H, Mori M, Sugimachi K. Serial histologic evaluation of multiple primary squamous
cell carcinomas of the esophagus. Cancer 1988;61:1635-8. 